Heuven, V.-Dislocatio glandulae lacrimalis. Nederl. Tijdschr. Geneesk. 1928, II : 3566 . Ref. Seidel.

KEYSER.-Un cas d'enchondrome du tarse de la paupiére supérieure. Ann. d'Ocul. $1895: 69,114$.

Michel, J.-Ein Fall von Anophthalmus Bilateralis. Gr. Arch. $f$. Augenheilk., $1878: 24,2: 71$.

Seidel, E.-Handb. d. spez. path. Anat. u. Histol. Henke-Lubarsch), Berlin. Vol. XI, p. 2. 1931.

\title{
THE DIAGNOSTIC AND CLINICAL VALUE OF SOME FORMS OF RETINAL ANGIOSPASM*
}

BY

N. Pines

LONDON.

THE scope of this paper is limited. It will not include spasm of the venous system, rarely seen but undoubtedly existing (it is frequently seen on the arms, when making an intravenous injection). And the chief interest, if any, of this paper is the connection it tries to establish between the ophthalmoscopic picture of the retina and the result of the general clinical examination, especially that of the arterial circulation. As far as bibliography is concerned, the writer thought it amply sufficient to refer only to two such monumental works on the subject as Bailliart's " Circulation Retinienne" and the Text-book of Ophthalmology by Sir Stewart Duke-Elder. The ophthalmoscope was the same old oneWolf's, with a red-free filter of green glass, with a 12 volt bulb, working to a maximum and to a short-life through a rheostat, attached to a carbon-bulb. It is important to achieve a very considerable degree of brilliancy to see clearly many details. Until the technique is mastered, it is advisable to dilate the patient's pupil and to work in a darkened room. This kind of observation puts a good deal of strain on the observer and must be of necessity short. Nor is the patient likely to stand it for a prolonged period, although the brilliancy of the light is mollified for him by the green filter. I did not find the mesh for measurement of the retinal vessels of much use.

\section{Physiological angiospasm}

In a perfectly healthy fundus, so rarely seen, because the translucency of the arterial wall is usually lost in childhood as a result of various infectious diseases, if the observer follows very carefully all the primary, secondary, etc., branches of the arteries, starting from their emerging point on the surface of the disc and scrutinising every bit up to the utmost periphery - the arteries are naturally

* Received for publication, August 23, 1945. 
becoming narrower and narrower but in a quite regular manner, i.e., the volume diminishes in perfect gradualness. There may be differences in different branches, but for one artery or one branch it is a rule. There are only two possible pitfalls in such a casethe artery runs on slightly different levels as far as the retina is concerned or, looking through the periphery of lens, the difference in refraction of the central and peripheral parts of the lens, may lead to this error-bits of an artery look different in volume-but with practice it is easy to avoid this mistake. In many healthy young men, usually below 30 years of age, in spite of translucency of the retinal vessels being absent, I found this gradual diminution of the arterial lumen present. But in the people of early middle age it is quite the opposite. You follow the artery say near the disc, not on the disc, where conditions are quite different, a tiny bit of it becomes slightly narrower, say to one tenth of its volume, and immediately after that the artery becomes again wider and then gradually narrows down till it disappears altogether. It looks

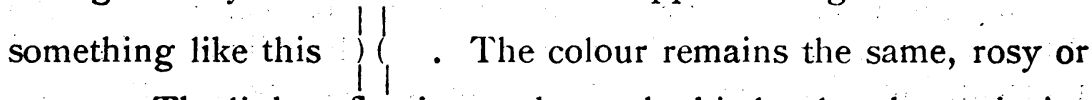
copper. The light reflex is not changed ; this local and very insignificant change is easily missed, unless kept in mind; it may affect tiny bits up to $1 / 20$ of a disc diameter-in the primary and secondary branches. I do not remember seeing much of it in the tertiary branches of healthy persons. But even more often and more clearly it is seen on the so-called "independent arteries," narrow and long, which join the main branch on the disc or deep by themselves into the substance of the disc.: I missed all these fine changes for many years - there is so much usually to see in the fundi and, as mentioned betore, the scrutinising must be very close, entirely concentrated in following all the arteries and therefore very tiresome indeed. Nor did I see this phenomenon described anywhere. I started to notice it myself only for the last few years in normal fundi. Very thorough investigation of all other retinal functions did not detect anything abnormal. I was puzzled for a long time, and then gradually a possible explanation dawned upon me, i.e., that the retinal picture is only a part of the general vascular makeup of the patient.

\section{Oscillometry}

In Pashon's oscillometer we have an ingenious instrument to measure the actual expansion of the arteries and arterioles, but not of capillaries, in the four limbs. It consists of an india-rubber cuff, applied round the end of the forearm (I use for the investigation the original Pashon's and not that of Gallavardin) as near to the wrist as possible, and the end of the calf as near as possible to the ankle. It is connected by an india-rubber tube with the box 
of the oscillometer; the whole of the system must be strictly airtight. Then air is pumped in and the sphygmomanometer on the top of the metallic box shows the height of the pressure in centimetres of mercury inside the cuff; now we stop pumping air-I usually palpate the pulse in the radial artery just below the cuffand depress a special automatic gadget, that immediately connects the cuff with the inside of the air-tight metallic box. Inside of this box is situated an aneroid tube connected with a needle, seen by an observer on the face of a graduated scale. With every systolic wave this needle is moving and shows the degree of expansion of the artery. The reader is referred for particulars to the original description of the oscillometer by Pashon. It is important to realise that oscillometry changes with the different height of bloodpressure, the systolic having the first increase, the mean bloodpressure having the maximum and the diastolic the smaller of readings. In my experience in quite healthy persons the oscillometric index for both upper limbs and for both lower limbs, but not for the upper and lower limbs together is nearly equal, the difference of 10 per cent. between corresponding limbs being not unusual, but 25 per cent. in my opinion, would be decidedly abnormal. Right wrist, for argument's sake 3 , left $3 \frac{1}{2}$; right ankle 6, left ankle 7. The lower limb usually gives a larger oscillometric reading than the upper one, due to increased blood supply. But in perfectly healthy subjects-without any blemish-so to say, the reading would be 3 and 3,6 and 6 . Even the 10 per cent. difference in reading must be due to some cause. And, in my opinion, there may be only two such possible causes, 1. the congenital slight difference in the blood supply, or 2. the play of vasomotors, i.e., angiospasm of mild (physiological degree).

If the difference is due to No. 1 , it ought to be constant for all the times. If it is due to No. 2-unless a serious pathological change is present-it ought to be changeable. And so it is. In examining the same subject again after a few weeks you may find R.W. $3 \frac{1}{2}$, L.W. 3, R. ankle 7, L.A. 6 or $6 \frac{1}{2}$. The combinations may be various and numberless. And invariably in those subjęcts I found this mild angiospasm of the retinal vessels, as described above. There is no parallelism in those two processes at all-a man can have extreme angiospasm in one or both of his legs-the oscillometer there would be 0 or $\frac{1}{2}$ against 3 or 4 in his upper limbs, but the retina will show only a mild degree of angiospasm-may be affecting not one, but a few of the branches, but nothing striking or corresponding to the state of vascular circulation in the lower limbs. The picture is still more complicated by the usual vascular retinal changes; due to atherosclerosis, involutional sclerosis and essential hyperpiesis. After all, the physiological angiospasm may be present in all of them and simply becomes exaggerated in pathological conditions. It is of the utmost importance to 
realise that the oscillometric readings are not of an absolute value, that they are highly individual, and important are only the differences in the corresponding readings. There is another corroboration of my opinion, that usually those differences are due to the play of vasomotors. Usually the systolic pressure is higher on the side, where oscillometric readings are smaller. It would be otherwise if those readings would be due to congenital narrowing. The diastolic and the mean-pressure may also be affected, but much more rarely. As an instance, here are the readings of a male, aged 35, a heavy smoker, and a neurasthenic, seen on September 17, 1939 ; R.W. $\frac{180(170)}{110-2}$, mean $120 ; \mathrm{L} . W . \frac{150(140)}{90-3}$, mean 100 , but both ankles were 4 . One of his indep. arteries is narrowed. On September 20th, 1939, another male, 23 years of age, had on $130(120)$

both wrists $\frac{130(120)}{90-3}$, both ankles 6 . Retina-nil special.

I must confess, that at the time I had not yet started to examine the retinal vessels scrupulously re angiospasm. If I am right in my deductions, then one result of those observations is of some importance-this physiological angiospasm of retinal arteries is part of a general one, i.e., the retina is subject to the influence of the general vasomotor centre. In the past I thought otherwise. But obviously some additional factor is interfering, helping the retinal vessels to some degree of independence because I see pretty often nearly complete absence of oscillometry in the lower limbs, but extremely rarely in the upper limbs, and still more rarely in the retina. Of course, no oscillometric reading is possible at all in the retinal vessels. What I meant is the difference in the frequency of the complete cessation of the circulation in the foot, as witnessed by gangrene and of a similar condition in the retina by thrombosis of the central artery. Or are both conditions seen nearly equally frequently? I am not in a position to decide this question, I can only dare to postulate it.

\section{Diastolic and mean retinal pressures}

After I came to certain conclusions re physiological retinal angiospasm, the obvious next step was to measure out the diastolic pressure, using the ingenious and reliable method of Bailliart. There is no necessity for me to describe this method. It requires some training. Fully applied, it requires the measurement of intraocular pressure as well. To this usually the patient objects. Therefore in the great majority of my cases I measure approximately the diastolic pressure only by applying Bailliart's tonometer on the upper lid. It is very inaccurate, of course, but still it helps to elucidate the picture, better than the simple digital compression of the 
ball. When you start to apply the dynamometer, you will find that at a certain point in the procedure there is a distinct trembling of the arterial tree on the disc and the blood stream presents a peculiar picture, I dare to say it stays undecided, which way to go. Your applied pressure, plus the intra-ocular one is equal to a diastolic retinal one. You slightly increase your pressure, and you see distinct arterial pulsation. The difference between two readings would partly represent, inter alia, also the actual measurement of the force of resistance of the arterial wall. It represents the mean blood pressure. In cases of physiological angiospasm of the retinal vessels I could not detect any difference between the contracted and non-contracted part of the arteries, provided their distance from the centre of the disc is equal. And my experience corresponds to that of Bailliart, that in the retinal vessels the diastolic pressure would be about 40 per cent. of the brachial one. It is usually equal in both eyes. I do not measure the systolic retinal pressure as it is not SQ important and requires rather a considerable outside pressure on the globe. In pathological cases, including those of mental anxiety, one may find a distinct difference in diastolic pressure on both sides, although a small one. Some claims for insurance payment in accident cases are peculiar. For distinct discomfort of some of the members of the medical fraternity, chiefly engaged in protecting the interests of the big insurance companies, this difference may remain for some time and usually disappears in a few weeks or months after the settlement of the claim. The same difference in the diastolic pressure may be present in cases of mild concussion of the brain. Additional to that is usually present the physiological angiospasm of the retinal arteries as described above, and the difference in oscillometric index of the four limbs. An additional difficulty is introduced by the age, say, of a person of 50, in regard of shape of the retinal arteries and of oscillometric index, but not of diastolic retinal pressure. From the other side extreme youth may prevent the appearance of the retinal angiospasm.

A boy aged 15 years met with a trivial accident when working on a tailor's cutting machine, as a result of some mechanical defect. A deep scar, not attached to the bone, goes through the tip of the left thumb. $\mathrm{He}$ is a scion of a highly neurotic family. He cannot $130(120)$.

work yet fully as à tailor's cutter.

R.W. $\frac{}{80-3} \mathrm{~mm} \cdot 85$, L.W. $\frac{110(100)}{80-1 \frac{1}{2}} \mathrm{~mm} .85$. Both ankles 5 . Both retinae-nil
abnormal. Three-quarters of an hour later, in the presence of the $120(110)$ 
Diagnostic and Clinical Value of Some

Forms of Retinal ANGIOSPASM

insurance company's doctor, R.W.

L.W. $\frac{100(90)}{80-\frac{1}{2}}$ mm. 85. The accident happened in September,

$80-1 \frac{1}{2}$

min. 85,

1943, I examined him on May 13, 1945.

This method of Bailliart is of utmost importance in pathological cases. A lady of over 50 years of age came to see me with blood 250

pressure $\frac{}{120}$ many years ago. She was under my care over 10 120

190

years, never having lower blood pressure than $\frac{190}{95}$, but usually 250

nearer $\frac{}{120}$. Advanced sclerosis of the retinal vessels, in later stage 120

also retinal haemorrhages and spots of retinomalacia, but not retinal oedema. Six months approximately before the end she complained of severe and persistent giddiness. A complete examination by Bailliart's method showed a diastolic retinal pressure of 25 with a brachial diastolic of 120 . Her giddiness was then due to cerebral hypo-and not to hypertension. This also pointed to the conclusion that her angiospasm is directed to the body, but not to brain.

A few months afterwards, with preceding dyspnoea, that was more disturbing than giddiness, she survived an attack of coronary thrombosis, but succumbed to the second one 6 or 8 weeks afterwards. It is important to notice that those forms of pathological angiospasm are usually not temporary, but persistent. The same applies to the physiological angiospasm. This is why Bailliart's method is so important by giving an additional diagnostic index in estimating the pressure in the changed retinal arteries.

If I may be allowed some freedom in fantastic schematising of all those phenomena-I wauld indicate two possible causes of events. Starting with an angiospasim, as an involutionary (or a defensive) reaction, providing the pressure in all branches of the vascular-tree is equal, a person lives to a ripe old age and only then develops the full picture of vascular degeneration, the capillary and parenchyma usually escaping, at least in the retina, as witnessed by absence of retinal haemorrhage, or retinomalacia. The other, much shorter way, is that of a vagotonic subject; he has not only an angiospasm, but also suffers from inequality of arterial pressure in different vascular branches. He develops much earlier 
all the signs of vascular degeneration, including that of the capillaries and parenchyma, he is subject to vascular accident, especially if essential hypertension is added to and the kidney function is impaired. But both are starting from the same physiological angiospasm. This spasm is an important and early sign, worth watching and pointing the way to dangerous possibility years ahead, but it is only a part of the clinical picture and must be included in the whole.

As mentioned above, the symptom by itself is only the-first step of the accommodation of the body to new condition of vascular life. It is usually not accompanied by a local rise in blood pressure. But if, measured by Bailliart's method, the diastolic pressure will be raised as well, usually it comes much later, and it precedes for some time the ophthalmoscopic changes in the retinal vessels, and the prognosis becomes much more alarming. I will even ask the indulgence of the reader for a generalisation. One way of vascular degeneration, accompanied by normal or even moderately elevated blood pressure is not liable to local angiospasms, allows the reaching of the ripe age, is characterised chiefly by a. v. compression and may be tortuosity of the arteries. This is the picture of senile fundus. The other one, in similat conditions of the blood pressure or with a very elevated sphygmomanometric reading, is liable in addition to local angiospasm, involving a whole area of the vascular tree, leading to vascular accidents or even exitus laethalis; in fundi the predominant picture is the change of the arterial wall and volume, haemorrhages, retinomalacia, etc. The clue in the diagnosis would be the sphygmometric, dynamometric (for the retina) and oscillometric readings together with the general clinical picture.

\section{BIBLIOGRAPHY}

BAILLIART.-La circulation retinienne, 1923.

DUKE-ELDER. - Text-book of ophthalmology.

PACHON ET FABRE.-Clinical curves of the cardiac function.

\section{REPORT ON A CASE OF HYDROPHTHALMIA (BUPHTHALMOS)}

BY

\section{E. Epstein, Major, R.A.M.C.}

THE following case is thought worth recording, for whereas the diagnosis of megalocornea might presumably have been made previously, the recent development of acute glaucoma in the right

* Received for publication, September 7, 1945. 